\title{
Navigation-Assisted Total Knee Arthroplasty for Patients with Extra-Articular Deformity
}

\author{
Seung Joon Rhee, MD, Chang Hyo Seo, MD, and Jeung Tak Suh, MD \\ Department of Orthopedic Surgery, Pusan National University Hospital, Busan, Korea
}

\begin{abstract}
Purpose: Since the existence of an extra-articular deformity seriously alters the normal geometry and kinetics around the knee joint, difficulties are often encountered in total knee arthroplasty (TKA) using a standard surgical technique. The purpose of this study was to evaluate the usefulness of surgical navigation system as a treatment option for osteoarthritic knees with extra-articular deformity.

Materials and Methods: The authors retrospectively reviewed medical records of the patients who underwent primary TKA between 2007 and 2012. Knees with preoperative radiography showing an angular deformity within the region from the middle third of the femur to the middle third of the tibia in the ipsilateral limb of the arthritic knees were considered as cases having extra-articular deformity. Thirteen knees of the 13 patients were found to have undergone TKA using a navigation system for osteoarthritis with ipsilateral extra-articular deformity. The hip-knee-ankle angle, Knee Society score (KSS), and range of motion were measured before and after the operation to evaluate the improvement.

Results: The mean hip-knee-ankle angle in the coronal plane was improved to $0.2^{\circ} \pm 4.5^{\circ}$ in valgus alignment postoperatively. The KSS was improved to $89.6 \pm 4.6$ points postoperatively at the last follow-up, with over $90 \%$ of good and excellent results. The range of motion was improved to $118.5^{\circ} \pm 10.5^{\circ}$ postoperatively.

Conclusions: Navigation-assisted TKA is a good treatment option of osteoarthritic knees with extra-articular deformity.
\end{abstract}

Keywords: Knee, Extra-articular, Deformity, Arthroplasty, Navigation

\section{Introduction}

Recovery of normal mechanical alignment with adequate soft tissue balancing is a key factor and a goal to successful total knee arthroplasty (TKA) ${ }^{1-4)}$. However, in the presence of extraarticular deformities of either the femur or the tibia, such a goal is much more difficult to achieve since the deformity aggravates the distortion of the 3-dimensional geometry of the arthritic knee. While the extra-articular deformity of the knee is commonly caused by malunion after a previous traumatic event, other

Received August 5, 2013; Revised (1st) October 7, 2013;

(2nd) October 30, 2013; Accepted November 11, 2013

Correspondence to: Jeung Tak Suh, MD

Department of Orthopedic Surgery, Pusan National University Hospital,

179 Gudeok-ro, Seo-gu, Busan 602-739, Korea

Tel: +82-51-240-7248, Fax: +82-51-247-8395

E-mail: jtsuh@pusan.ac.kr

This is an Open Access article distributed under the terms of the Creative Commons Attribution Non-Commercial License (http://creativecommons.org/licenses/by-nc/3.0/) which permits unrestricted non-commercial use, distribution, and reproduction in any medium, provided the original work is properly cited. situations likes stress fractures, previous surgical interventions, metabolic bone disease can also be possible reasons ${ }^{5,6)}$. Altered mechanical axis of the lower limb and anatomic landmarks interfere with correct implantation of TKA components, and this can be a reason of malalignment that can lead to patellar maltracking, early loosening, higher rates of polyethylene wear ${ }^{1-5,7)}$. Retained hardware and canal sclerosis, which are frequently seen in patients with extra-articular deformity, can also be an obstacle in TKA. Under such abnormal situations, usage of conventional instrumentations of TKA including intramedullary femoral guide and intra- and extramedullary tibial guide is highly restricted.

TKA in knees with extra-articular deformity can be done through staged or one-stage operation. The lower incidences of anesthesia, operation and complication are the relative advantages of one-stage operation over staged operation. Surgical navigation system can be a good option that facilitates simultaneous treatment of osteoarthritis and extra-articular deformity of the knee. The purpose of this study was to report good clinical and radiological results of navigation-assisted TKA for osteoarthritic knees with extra-articular deformity. 


\section{Materials and Methods}

Authors retrospectively reviewed medical records of the patients who underwent primary TKA between 2007 and 2012 to enroll the cases with extra-articular deformity. Knees with preoperative radiography showing angular deformity in the middle or distal third of the femur or in the proximal or middle third of the tibia with or without involvement of the articular surface in the ipsilateral limb of the arthritic knees were considered as having extra-articular deformity ${ }^{6}$. Thirteen knees of 13 patients were found to have had ipsilateral extra-articular deformity associated with arthritic knees. All of the patients underwent TKA and intra-articular correction of the extra-articular deformity using navigation system. There were 4 male and 9 female patients, and their average age at operation was 69 years (range, 52 to 83 years). Extra-articular deformities were located in the femur in 9 patients, and tibia in 4 patients. There were 3 uniplanar and 10 biplanar deformities. The mean follow-up period was 3.1 years. All deformities were caused by malunion of fracture. Three patients had retained hardware due to prior operation for trauma. The average interval between the initial trauma and operation was 26 years (range, 10 to 42 years) (Table 1 ).

Preoperative and postoperative orthoroentgenogram (anteroposterior full-length weight-bearing radiography) of all the patients were checked. The hip-knee-ankle axis and angulation in both coronal and sagittal planes of the femur or tibia were measured (Fig. 1). For femoral deformities, on the preoperative orthoroentgenogram, the proposed distal femoral cut was drawn perpendicular to the mechanical axis of the femur. If the deformity was more than $20^{\circ}$ or if the plane of the distal cut compro-

Table 1. Data on the Extra-Articular Deformity and Pre- (Preop) and Postoperative (Postop) Hip-Knee-Ankle Axis, Knee Society Score (KSS), Range of Motion (ROM) of the Knee

\begin{tabular}{|c|c|c|c|c|c|c|c|c|c|c|c|c|c|c|c|c|}
\hline \multirow[t]{2}{*}{ Case } & \multirow[t]{2}{*}{ Sex } & \multirow{2}{*}{$\begin{array}{l}\text { Age } \\
(\mathrm{yr})\end{array}$} & \multirow{2}{*}{$\begin{array}{c}\text { Preop } \\
\text { diagnosis }\end{array}$} & \multirow{2}{*}{$\begin{array}{l}\text { PTD } \\
(\mathrm{yr})\end{array}$} & \multicolumn{4}{|c|}{ Deformity } & \multicolumn{2}{|c|}{$\begin{array}{c}\text { Hip-knee-ankle } \\
\text { axis }\left({ }^{\circ}\right)\end{array}$} & \multicolumn{2}{|c|}{ KSS } & \multicolumn{2}{|c|}{$\operatorname{ROM}\left({ }^{\circ}\right)$} & \multirow{2}{*}{$\begin{array}{l}\text { Retained } \\
\text { hardware }\end{array}$} & \multirow{2}{*}{$\begin{array}{l}\text { Type of } \\
\text { implant }\end{array}$} \\
\hline & & & & & Site (1) & Site (2) & Plane & Degree & Preop & Postop & Preop & Postop & Preop & Postop & & \\
\hline 1 & $\mathrm{M}$ & 83 & $\begin{array}{l}\text { Fracture } \\
\text { malunion }\end{array}$ & 33 & Femur & Middle 1/3 & Axial & Extorsion 10 & -8 & 2 & 32 & 85 & 85 & 120 & $\mathrm{x}$ & $\begin{array}{l}\text { Zimmer- } \\
\text { LPS-Flex }\end{array}$ \\
\hline 2 & $\mathrm{M}$ & 82 & $\begin{array}{l}\text { Fracture } \\
\text { malunion }\end{array}$ & 40 & Femur & Middle $1 / 3$ & $\begin{array}{l}\text { Axial } \\
\text { Coronal }\end{array}$ & $\begin{array}{l}\text { Intorsion } 30 \\
\text { Varus } 4\end{array}$ & -2 & 0 & 35 & 87 & 85 & 120 & $\mathrm{x}$ & $\begin{array}{l}\text { Zimmer- } \\
\text { LPS-Flex }\end{array}$ \\
\hline 3 & $\mathrm{M}$ & 75 & $\begin{array}{l}\text { Fracture } \\
\text { malunion }\end{array}$ & 24 & Femur & Middle 1/3 & $\begin{array}{l}\text { Coronal } \\
\text { Sagittal }\end{array}$ & $\begin{array}{l}\text { Valgus } 3 \\
\text { Retrocurvatum } 2\end{array}$ & 7 & -2 & 19 & 88 & 125 & 135 & $\mathrm{x}$ & $\begin{array}{l}\text { Zimmer- } \\
\text { LPS-Flex }\end{array}$ \\
\hline 4 & $\mathrm{~F}$ & 77 & $\begin{array}{l}\text { Fracture } \\
\text { malunion }\end{array}$ & 17 & Femur & Middle $1 / 3$ & $\begin{array}{l}\text { Coronal } \\
\text { Sagittal }\end{array}$ & $\begin{array}{l}\text { Varus } 3 \\
\text { Retrocurvatum } 2\end{array}$ & 13 & 0 & 29 & 95 & 100 & 125 & $\mathrm{x}$ & $\begin{array}{l}\text { Zimmer- } \\
\text { LPS-Flex }\end{array}$ \\
\hline 5 & $\mathrm{~F}$ & 76 & $\begin{array}{l}\text { Fracture } \\
\text { malunion }\end{array}$ & 40 & Femur & Middle 1/3 & $\begin{array}{l}\text { Coronal } \\
\text { Sagittal }\end{array}$ & $\begin{array}{l}\text { Varus } 18 \\
\text { Retrocurvatum } 10\end{array}$ & 25 & 0 & 34 & 97 & 60 & 115 & $\mathrm{x}$ & $\begin{array}{l}\text { Zimmer- } \\
\text { LPS-Flex }\end{array}$ \\
\hline 6 & $\mathrm{~F}$ & 62 & $\begin{array}{l}\text { Fracture } \\
\text { malunion }\end{array}$ & 38 & Femur & Distal 1/3 & Sagittal & Retrocurvatum 18 & 13 & 4 & 32 & 90 & 100 & 130 & $\mathrm{x}$ & $\begin{array}{l}\text { Zimmer- } \\
\text { LPS-Flex }\end{array}$ \\
\hline 7 & $\mathrm{~F}$ & 70 & $\begin{array}{l}\text { Fracture } \\
\text { malunion }\end{array}$ & 23 & Femur & Distal 1/3 & Sagittal & Antecurvatum 10 & 5 & 0 & 35 & 92 & 75 & 110 & o & $\begin{array}{l}\text { Zimmer- } \\
\text { LPS-Flex }\end{array}$ \\
\hline 8 & $\mathrm{~F}$ & 68 & $\begin{array}{l}\text { Fracture } \\
\text { malunion }\end{array}$ & 37 & Femur & Distal 1/3 & $\begin{array}{l}\text { Coronal } \\
\text { Sagittal }\end{array}$ & $\begin{array}{l}\text { Varus } 15 \\
\text { Retrocurvatum } 12\end{array}$ & 1 & -2 & 35 & 93 & 90 & 115 & $\mathrm{x}$ & $\begin{array}{l}\text { Zimmer- } \\
\text { LPS-Flex }\end{array}$ \\
\hline 9 & M & 57 & $\begin{array}{l}\text { Fracture } \\
\text { malunion }\end{array}$ & 10 & Femur & Distal 1/3 & $\begin{array}{l}\text { Coronal } \\
\text { Sagittal }\end{array}$ & $\begin{array}{l}\text { Valgus } 10 \\
\text { Antecurvatum } 6\end{array}$ & -13 & -13 & 21 & 80 & 85 & 125 & o & Depuy PFC \\
\hline 10 & $\mathrm{~F}$ & 65 & $\begin{array}{l}\text { Fracture } \\
\text { malunion }\end{array}$ & 13 & Tibia & Proximal 1/3 & $\begin{array}{l}\text { Coronal } \\
\text { Sagittal }\end{array}$ & $\begin{array}{l}\text { Varus } 5 \\
\text { Antecurvatum } 15\end{array}$ & 17 & 0 & 24 & 92 & 70 & 105 & $\mathrm{x}$ & $\begin{array}{l}\text { Zimmer- } \\
\text { LPS-Flex }\end{array}$ \\
\hline 11 & $\mathrm{~F}$ & 83 & $\begin{array}{l}\text { Fracture } \\
\text { malunion }\end{array}$ & 23 & Tibia & Proximal 1/3 & $\begin{array}{l}\text { Coronal } \\
\text { Sagittal }\end{array}$ & $\begin{array}{l}\text { Varus } 10 \\
\text { Retrocurvatum } 3\end{array}$ & 21 & 3 & 22 & 85 & 95 & 130 & $\mathrm{x}$ & Depuy PFC \\
\hline 12 & $\mathrm{~F}$ & 57 & $\begin{array}{l}\text { Fracture } \\
\text { malunion }\end{array}$ & 15 & Tibia & Proximal 1/3 & $\begin{array}{l}\text { Coronal } \\
\text { Sagittal }\end{array}$ & $\begin{array}{l}\text { Valgus } 10 \\
\text { Antecurvatum } 26\end{array}$ & -4 & -1 & 29 & 89 & 50 & 100 & $\mathrm{x}$ & $\begin{array}{l}\text { Zimmer- } \\
\text { LPS-Flex }\end{array}$ \\
\hline \multirow[t]{2}{*}{13} & $\mathrm{~F}$ & 52 & $\begin{array}{l}\text { Fracture } \\
\text { malunion }\end{array}$ & 25 & Tibia & Proximal 1/3 & $\begin{array}{l}\text { Coronal } \\
\text { Sagittal }\end{array}$ & $\begin{array}{l}\text { Varus } 20 \\
\text { Antecurvatum } 17\end{array}$ & 18 & 6 & 28 & 92 & 65 & 110 & o & Depuy PFC \\
\hline & & & & $26^{\text {a) }}$ & & & & & $7.15^{\mathrm{a})}$ & $-0.23^{\mathrm{a})}$ & $28.85^{\text {a) }}$ & $89.62^{\text {a) }}$ & $83.46^{\mathrm{a})}$ & $118.46^{\mathrm{a})}$ & & \\
\hline
\end{tabular}

PTD: posttraumatic duration, Hip-knee-ankle axis: +, varus; -, valgus.

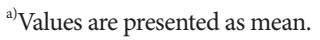


mised the collateral ligament attachment, other surgical options, such as corrective osteotomy, was considered. For tibial deformities, the proposed proximal tibial cut was drawn perpendicular to the mechanical axis of the tibia. If the distal tibial axis did not pass through the tibial plateau or if the deformity was more than $30^{\circ}$, other surgical options, such as corrective osteotomy, was considered.

Preoperative orthoroentgenogram and anteroposterior and lateral radiographs of the knee were exported from the PACS, Marosis m-view 5.4 (Marotech Inc., Seoul, Korea) program as a
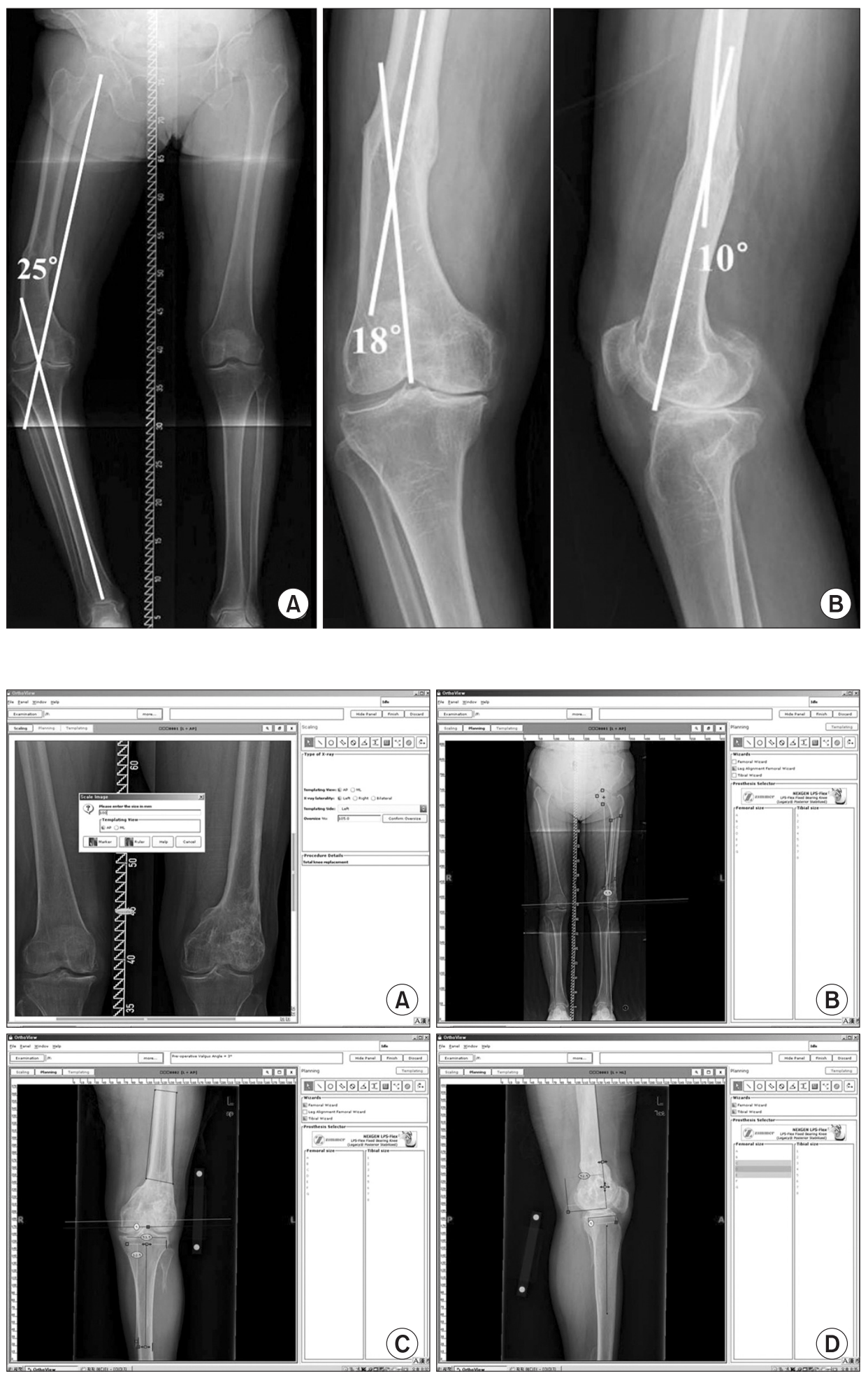

Fig. 1. (A) Measurement of the preoperative hip-knee-ankle axis using orthoroentgenogram (anteroposterior full-length weightbearing radiography), which is showing $25^{\circ}$ of varus. (B) Measurement of the femoral anatomical axis deformity using anteroposterior and lateral knee radiography, which is showing $18^{\circ}$ of varus and $10^{\circ}$ of retrocurvatum.
Fig. 2. Preoperative templating using Orthoview (Meridian Technique Limited) program and imported JPG images: (A) Resizing using a $10 \mathrm{~cm}$ ruler, (B) Measuring of the femoral alignment, (C) Measuring of the size of the femur and tibia in the coronal plane, (D) Measuring of the size of the femur and tibia in the sagittal plane. 

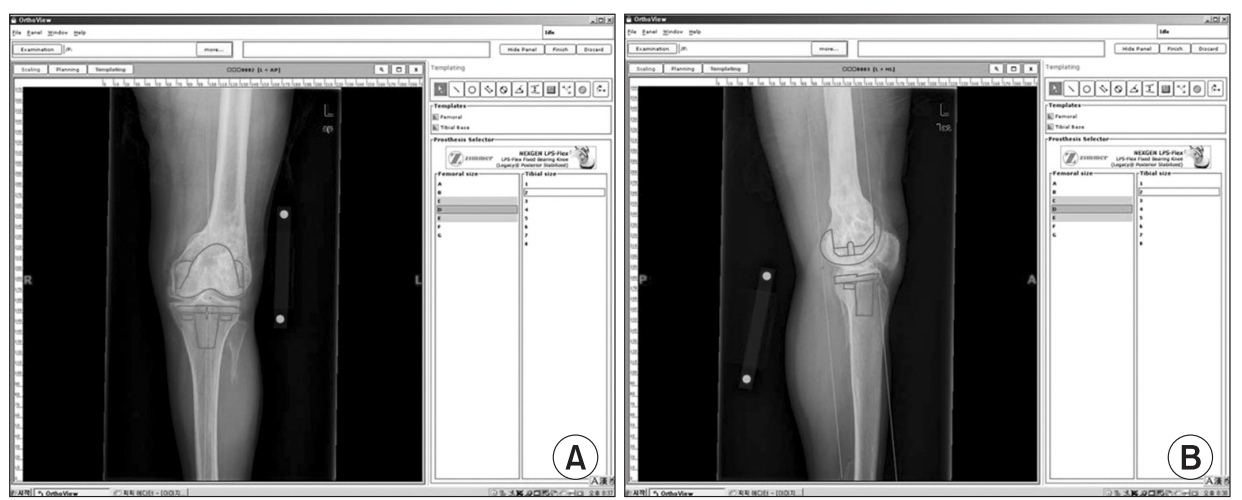

Fig. 3. Determination of the implant size based on the measurement results on the coronal plane (A) and sagittal plane (B).
JPG file. Then, templating was done using Orthoview (Meridian Technique Limited, Southampton, UK) program and exported JPG images. After re-sizing the images to match the size of the $10 \mathrm{~cm}$ ruler as a first step, leg alignment was measured using the alignment tool. Then, the size and shape of the femur and tibia in the coronal and sagittal planes was measured (Fig. 2). As a final step, template of the femur and tibia was overlapped in the coronal and sagittal plane to approximate the proper size of the implants and to look for any deformity that would be an obstacle to component placement (Fig. 3). Assessment to determine the need for augmentation using bone grafts, wedges, or stem extensions was done. In this series, no bone graft was required in the real operation, but metal block augmentation was required in 3 cases in the femoral side and tibial stem extension was used in 1 case. Knee Society score (KSS) was assessed before and after the operation.

All the operations were performed by a single surgeon. Two different TKA designs were implanted, NexGen LPS-Flex (Zimmer Inc., Warsaw, IN, USA) in 10 patients and P.F.C. Sigma (DePuy Orthopaedics Inc., Warsaw, IN, USA) in 3 patients. In all cases, TKAs were performed using an image free Medtronic Electromagnetic knee navigation system (Zimmer Inc.).

Medial parapatellar arthrotomy was performed using an anterior midline approach in 11 patients, whereas, in patients who had a previous knee surgery, the procedure was carried out through the original incision site to avoid skin necrosis or additional scarring. Then, navigation tracker fixation was done by inserting two pins in the distal femur and proximal tibia. The location of the hip joint center was identified as the average center of a large and three-planar femur-to-pelvis rotation. Since Medtronic Electromagnetic knee navigation system (Zimmer Inc.) is an image free navigation system that uses a surface mapping guide for the placement of the cutting guides, registration of anatomical landmarks and axes including femur anteroposterior axis and the medial and lateral epicondyles with instrumented pointer was per- formed to define the anatomical reference frames for the femur and tibia, which provided target orientations for all relevant bone cuts and rotational alignment. Bone cutting was planned for the distal femur and proximal tibia separately with regard to the mechanical axis of each bone. The distal femoral bone cut was at $0^{\circ}$ in the coronal plane and at $3^{\circ}$ of flexion in the sagittal plane, and the proximal tibial cut was at $0^{\circ}$ in the frontal plane and $5^{\circ}$ posterior slope in the sagittal plane. For rotational alignment, the epicondylar axis and the Whiteside line were taken for the femur ${ }^{8)}$. Tibial trial was left free to rotate during cycles of knee flexion and extension, and the orientation in full extension was chosen for its optimal rotational alignment.

Following those bone cutting, the extension gap or flexion gap was seen in trapezoid rather than rectangular shape. But, both collateral ligament insertions were all intact. Soft tissue balancing was performed during the trial component placement and after the final component placement under the guidance of the navigation system.

Orthoroentgenogram was obtained immediately after surgery, 1 month postoperatively, and consecutively at follow-up. The follow-up period was 3.1 years on average. The femoral mechanical axis was defined as a line drawn from the hip center to the deepest part of the femoral intercondylar notch, and tibial mechanical axis as a line drawn from the midpoint of the tibial spine to the midpoint of the talar dome. The hip-knee-ankle angles were measured using those axes (Fig. 1A). The range of motion and KSS were also recorded for clinical evaluation.

\section{Results}

The mean preoperative hip-knee-ankle angle in the coronal plane was $7.2^{\circ} \pm 11.8^{\circ}$ in varus alignment (range, $25^{\circ}$ varus to $13^{\circ}$ valgus). Of the 9 femoral extra-articular deformities, 5 were in the middle third and 4 were in the distal third of the femur. The mean femoral angular deformity was varus $3.4^{\circ}$ in the coronal 

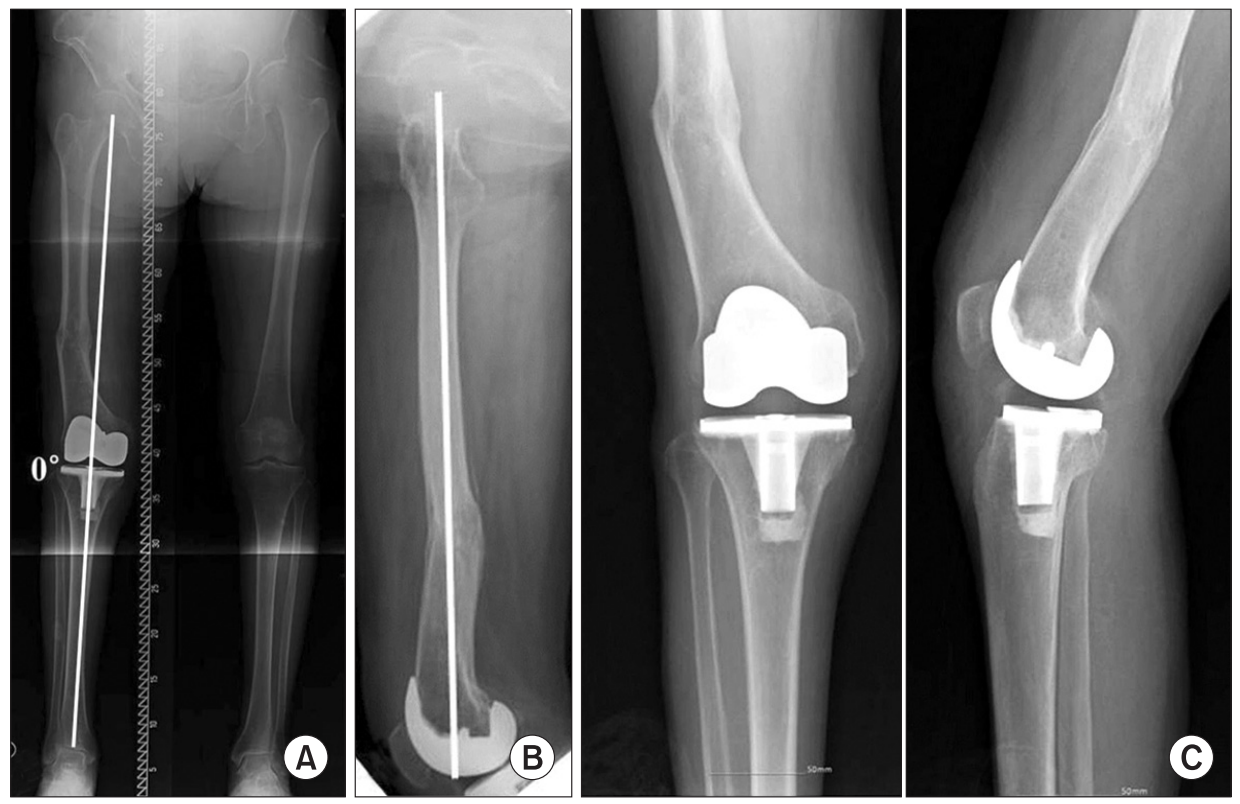

Fig. 4. Postoperative radiographs showing the results of navigation-assisted total knee arthroplasty in case No. 5: $0^{\circ}$ hip-kneeankle axis (A), $0^{\circ}$ femoral mechanical axis in the sagittal plane (B), and anteroposterior and lateral knee radiographs (C).

plane and $4.0^{\circ}$ recurvatum in the sagittal plane. All 4 tibial extraarticular deformities were in the proximal third of the tibia. The mean angular deformity of the tibia was $6.3^{\circ}$ varus in the coronal plane and $13.8^{\circ}$ antecurvatum in the sagittal plane. At the postoperative follow-up, it was $0.2^{\circ} \pm 4.5^{\circ}$ in valgus alignment (range, $6^{\circ}$ varus to $13^{\circ}$ valgus) (Fig. 4). The KSS was improved from $28.8 \pm 5.7$ points preoperatively (range, 19 to 35 points) to $89.6 \pm 4.6$ points at the last follow-up (range, 80 to 97 points), with over $90 \%$ of good and excellent results. The range of motion was improved from a mean of $83.5^{\circ} \pm 19.8^{\circ}$ preoperatively (range, $50^{\circ}$ to $125^{\circ}$ ) to $118.5^{\circ} \pm 10.5^{\circ}$ postoperatively (range, $100^{\circ}$ to $135^{\circ}$ ) (Table 1).

\section{Discussion}

Currently, operation assisted by a navigation system is often performed in various surgical fields. Navigation helps surgeons identify what they are doing and how they are doing by visualizing the surgical field with reconstructed images or representative numbers and guides throughout the operation. It is helpful for avoiding serious mistakes during surgery and ultimately reducing postoperative complication rates. This is not an exception in the field of orthopaedics, and TKA is a renowned example of navigation applicable orthopaedic surgery. The advantages with respect to component alignment and soft tissue balancing are already well established in several studies ${ }^{9-17)}$. The importance of this study lies in that authors applied the navigation system for TKA in patients with extra-articular deformity. Since the existence of an extra-articular deformity seriously alters the normal geometry and kinetics around the knee joint, difficulties are often encounter in operations using standard surgical techniques. So, surgical strategies, such as simultaneous femoral osteotomy with TKA and staged TKA following corrective osteotomy, were adapted to overcome such an unfavorable condition and achieve successful TKA in patients with extra-articular deformity. There are reports showing good clinical and radiological results of those traditional staged surgery, but staged surgery is inevitably affected by complications including infections, arthrofibrosis, and nonunion of the osteotomy site. Since Wang and Wang ${ }^{6}$ first reported intraarticular bone resection could be a new alternative surgical strategy in correcting extra-articular deformity, despite the risk associated with collateral ligament injury and grossly asymmetric gap, this technique has become the common choice of surgery. Less incision, lower incidence of complications, and earlier rehabilitation are good reasons to prefer intra-articular bone resection in the correction of extra-articular deformity. Moreover, combined use of a navigation system made this surgical option more preferable by effectively overcoming the difficulties. Navigation systems provide information on accurate bone cutting, proper orientation of prosthesis component, and soft tissue balancing under the situation that operators cannot recognize normal anatomical landmarks or insert intramedullary guide due to the extra-articular deformity of the femur or tibia.

There were 9 femoral extra-articular deformities and 4 tibial extra-articular deformities in our study. Although their causative deformities were located either in the femur or the tibia alone, 
the deformity affected the whole lower limb and changed the limb alignment significantly. So, the treatment and evaluation of surgical results were focused on the correction of the hip-kneeankle angle. We designed our operative goal to neutralize the hipknee-ankle angle to $0^{\circ}$. In the operative field, we confirmed that the hip-knee-ankle angle was corrected to $0^{\circ}$ in all cases, but the postoperative hip-knee-ankle angle was not the same as the intraoperative measurement on the postoperative orthoroentgenogram. In the weight loaded standing orthoroentgenogram, we identified $0^{\circ}$ of hip-knee-ankle angle in 5 cases and less than $2^{\circ}$ of deviation from $0^{\circ}$ in 4 cases, but the rest 4 cases showed more than $2^{\circ}$ of deviation from $0^{\circ}$. We consider that the less than $2^{\circ}$ of hip-knee-ankle angle deviation might be due to the characteristic errors of electromagnetic navigation and somewhat inevitable. Since the electromagnetic navigation system makes calculations based on the data transmitted from the trackers, the erroneous fixation of trackers on the wrong position or inadvertent movement of trackers can distort the resultant presentation. For the 4 cases with over $2^{\circ}$ of hip-knee-ankle angle deviation, we suspect ligament balancing was a major problem. Due to the severe soft tissue contractures associated with poor arc of knee motion and compromised, scarred soft tissue, patients required extensive soft tissue and ligamentous release and even collateral ligament reconstruction. So, we suspect poor preoperative soft tissue condition and unsatisfactory ligamentous balancing could have been the reasons for unsatisfactory hip-knee-ankle angle correction.
Especially, case No. 9 had shown severe valgus instability gait due to the numerous and long standing series of operations for his trauma and posttraumatic arthritis, muscle weakness around the knee joint was severe, and the laxity of medial collateral ligament was disastrous, and even after our operation, the limb alignment returned to valgus position again (Fig. 5). In our opinion, the operations on cases with hip-knee-ankle angle deformities exceeding $15^{\circ}$ in any direction are more difficult. However, it needs to be proven statistically with detailed parameters later based on accumulated cases.

There were 2 cases with rotational deformities in the femur. Case No. 1 had $10^{\circ}$ externally rotated femur as a result of traumatic deformity. But, in this case, we didn't concern much about the rotational alignment itself because the patient had fully adapted to his rotational problem with subclinical gait abnormality. For case No. 2, a detailed study of rotational alignment was done before the operation because of apparent rotational deformity in the orthoroentgenogram. Preoperative computed tomography revealed that his femoral anteversion was about $46^{\circ}$, which was about $30^{\circ}$ internally rotated than normal range. However, rotational deformity itself couldn't be corrected by intra-articular correction. Even $10^{\circ}$ correction would injure the collateral ligament insertion and possibly cause seriously imbalanced posterior condylar resection. Soft tissue release could not achieve the balance, either. So, in this case we decided to correct the hip-kneeankle angle only (Fig. 6).
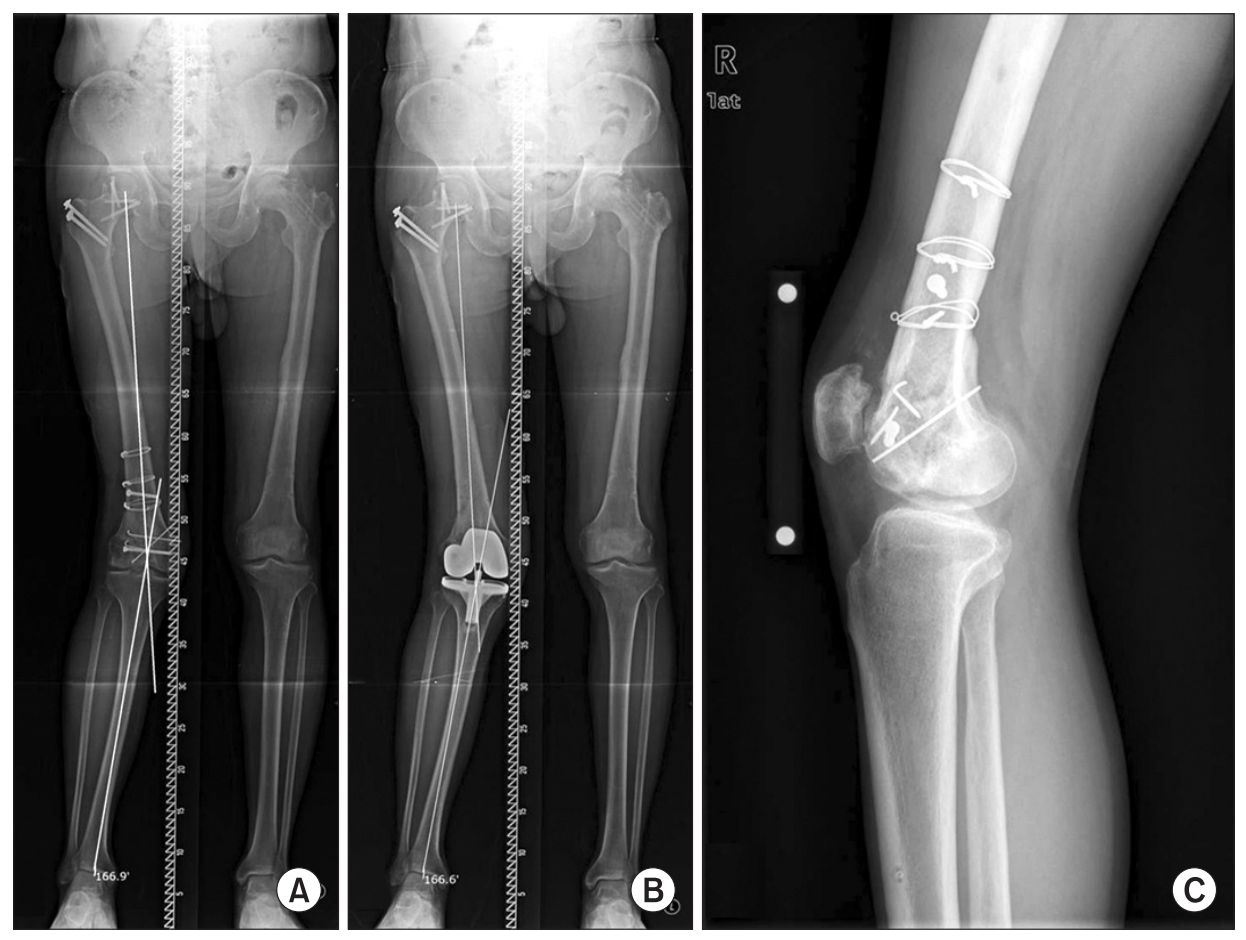

Fig. 5. Radiographic images of case No. 9: $13^{\circ}$ of valgus hip-knee-ankle axis in the preoperative orthoroentgenogram (A), $13^{\circ}$ of valgus hip-knee-ankle axis in the 1-month postoperative orthoroentgenogram (B), and preoperative lateral knee radiograph showing the retained hardware in the distal femur (C). 

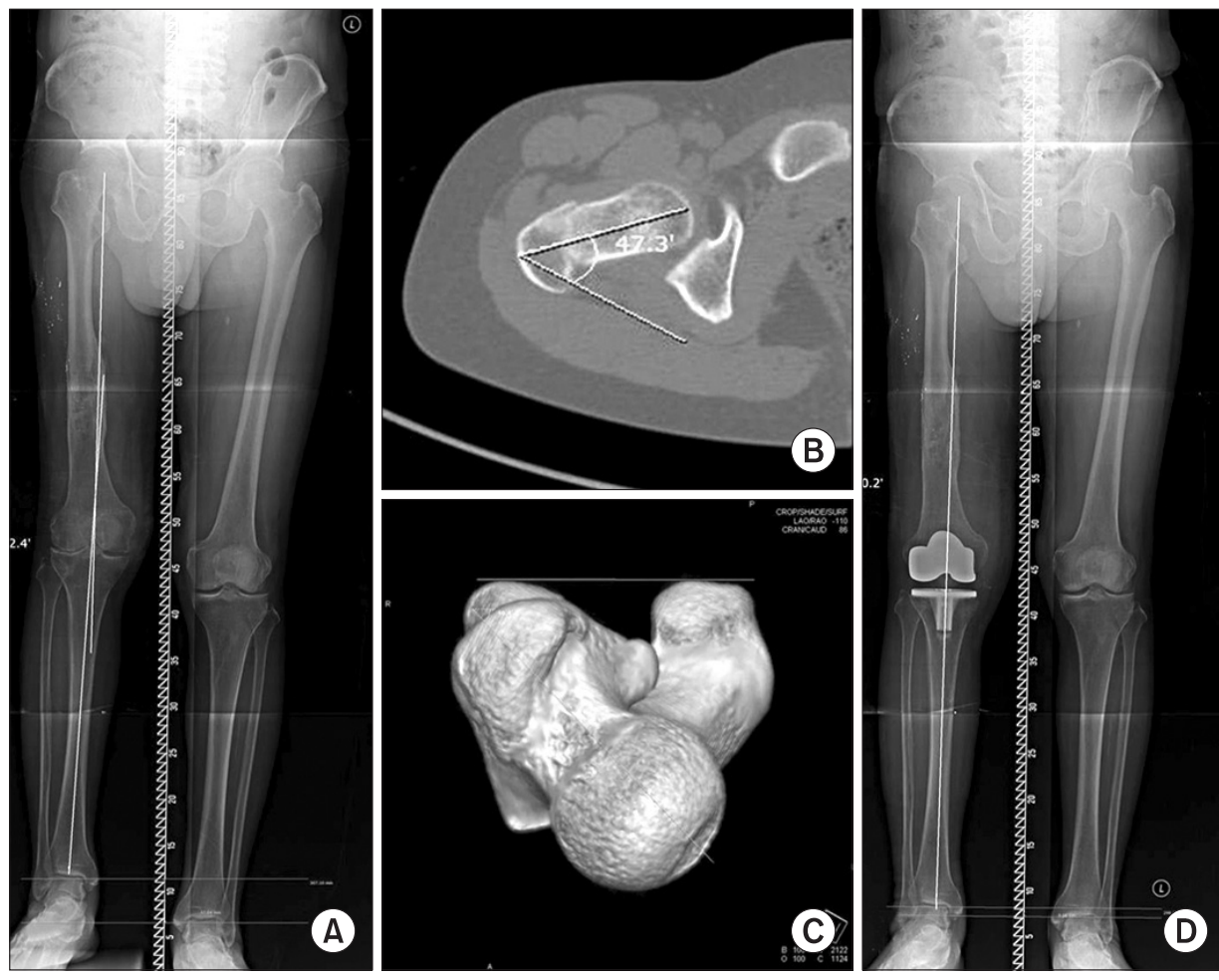

Fig. 6. (A) Preoperative orthoroentgenogram showing $2^{\circ}$ of valgus hip-knee-ankle axis with large, externally rotated lesser trochanter implying internally rotated extra articular deformity. (B) Axial computed tomography showing $47.3^{\circ}$ of anterversion of the femur. (C) Reconstructed image of the femur showing $46^{\circ}$ of anterversion. (D) Postoperative orthoroentgenogram showing $0^{\circ}$ of hip-knee-ankle axis with the knee joint still internally rotated.
There were 3 cases with remaining hardware of past trauma operation. Case No. 7 had a cerclage wire in the femur and Case No. 13 had 2 cerclage wires in the proximal tibia. But they didn't disturb any procedure related to the navigation-assisted TKA. Case No. 9 had multiple cerclages wires, Kirshner wires and screws in the distal femur that would probably be an obstacle if it were a conventional TKA using intramedullary cutting guide (Fig. 5). However, by using the navigation, TKA could be performed relatively with ease and necessitated minimum removal of the remaining hardware. But, the remaining hardware was removed to lower the risk of infection and patient discomfort.

As for complication, partial patellar tendon detachment occurred in 2 cases. Primary repair using Ethibond suture was done in the operative field. Their knees were immobilized for 6 weeks postoperatively with subsequent uncomplicated healing and full restoration of extensor mechanism function.

The advantages of navigation-assisted TKA in knees with extraarticular deformity lie in the planning and assessment of the most adequate planes for the bone cuts, guidance of the surgeon to avoid compromising the epicondyles and the consequent imbalance of the ligaments. In addition, the use of a navigation system instead of intramedullary rods reduces blood loss and the potential risk of fat emboli since the intramedullary canal remains intact ${ }^{18,19)}$. Prolonged operative time and cost is a problem that needs to be overcome when using a navigation system in
TKA. Finally, after removal of the hardware, the remaining holes can be sites for stress with an associated increase in the rate of the periprosthetic fractures ${ }^{7,20,21)}$.

The limitation of our study is that the number of patients was too small due to the rarity of TKA with extra-articular deformity. High standard of fracture treatment left not so many cases of residual deformity, which the authors tried to look for. For these reasons, further meaningful statistical analysis couldn't be done. In addition, comparison between navigation-assisted and conventional TKAs couldn't be carried out, because the authors only included the cases with TKA using a navigation system.

\section{Conclusions}

Navigation-assisted TKA could enable mechanical axis correction of the lower extremity without separate corrective osteotomy in the selected patients with osteoarthritic knees and extra-articular deformities. Since the navigation helped us idenfity the anatomical parameters, we could overcome the limitations caused by the extra-articular deformity and achieve near normal alignment with relatively few difficulties. The postoperative improvement in the hip-knee-ankle angle, KSS, range of motion proved the effectiveness of a navigation system in TKA. We think that navigationassisted TKA is a good treatment option for osteoarthritic knees with extra-articular deformity. 


\section{Conflict of Interest}

No potential conflict of interest relevant to this article was reported.

\section{Acknowledgments}

This work was supported by a 2-Year Research Grant of Pusan National University.

\section{References}

1. Berger RA, Rubash HE, Seel MJ, Thompson WH, Crossett LS. Determining the rotational alignment of the femoral component in total knee arthroplasty using the epicondylar axis. Clin Orthop Relat Res. 1993;(286):40-7.

2. Oswald MH, Jakob RP, Schneider E, Hoogewoud HM. Radiological analysis of normal axial alignment of femur and tibia in view of total knee arthroplasty. J Arthroplasty. 1993;8:419-26.

3. Wasielewski RC, Galante JO, Leighty RM, Natarajan RN, Rosenberg AG. Wear patterns on retrieved polyethylene tibial inserts and their relationship to technical considerations during total knee arthroplasty. Clin Orthop Relat Res. 1994;(299):31-43.

4. Garg A, Walker PS. Prediction of total knee motion using a three-dimensional computer-graphics model. J Biomech. 1990;23:45-58.

5. Lonner JH, Siliski JM, Lotke PA. Simultaneous femoral osteotomy and total knee arthroplasty for treatment of osteoarthritis associated with severe extra-articular deformity. J Bone Joint Surg Am. 2000;82:342-8.

6. Wang JW, Wang CJ. Total knee arthroplasty for arthritis of the knee with extra-articular deformity. J Bone Joint Surg Am. 2002;84:1769-74.

7. Bottros J, Klika AK, Lee HH, Polousky J, Barsoum WK. The use of navigation in total knee arthroplasty for patients with extra-articular deformity. J Arthroplasty. 2008;23:74-8.

8. Whiteside LA, Arima J. The anteroposterior axis for femoral rotational alignment in valgus total knee arthroplasty. Clin Orthop Relat Res. 1995;(321):168-72.

9. Bathis H, Perlick L, Tingart M, Luring C, Zurakowski D, Grifka J. Alignment in total knee arthroplasty: a comparison of computer-assisted surgery with the conventional technique. J Bone Joint Surg Br. 2004;86:682-7.

10. Bathis H, Shafizadeh S, Paffrath T, Simanski C, Grifka J, Lur- ing C. Are computer assisted total knee replacements more accurately placed? A meta-analysis of comparative studies. Orthopade. 2006;35:1056-65.

11. Bolognesi M, Hofmann A. Computer navigation versus standard instrumentation for TKA: a single-surgeon experience. Clin Orthop Relat Res. 2005;440:162-9.

12. Chauhan SK, Scott RG, Breidahl W, Beaver RJ. Computerassisted knee arthroplasty versus a conventional jig-based technique: a randomised, prospective trial. J Bone Joint Surg Br. 2004;86:372-7.

13. Ensini A, Catani F, Leardini A, Romagnoli M, Giannini S. Alignments and clinical results in conventional and navigated total knee arthroplasty. Clin Orthop Relat Res. 2007;457:156-62.

14. Hart R, Janecek M, Chaker A, Bucek P. Total knee arthroplasty implanted with and without kinematic navigation. Int Orthop. 2003;27:366-9.

15. Jenny JY, Clemens U, Kohler S, Kiefer H, Konermann W, Miehlke RK. Consistency of implantation of a total knee arthroplasty with a non-image-based navigation system: a case-control study of 235 cases compared with 235 conventionally implanted prostheses. J Arthroplasty. 2005;20:832-9.

16. Luring C, Oczipka F, Perlick L, Tingart M, Grifka J, Bathis $\mathrm{H}$. Two year follow-up comparing computer assisted versus freehand TKR on joint stability, muscular function and patients satisfaction. Knee Surg Sports Traumatol Arthrosc. 2009;17:228-32.

17. Sparmann M, Wolke B, Czupalla H, Banzer D, Zink A. Positioning of total knee arthroplasty with and without navigation support: a prospective, randomised study. J Bone Joint Surg Br. 2003;85:830-5.

18. Kalairajah Y, Cossey AJ, Verrall GM, Ludbrook G, Spriggins AJ. Are systemic emboli reduced in computer-assisted knee surgery?: a prospective, randomised, clinical trial. J Bone Joint Surg Br. 2006;88:198-202.

19. Jeon SH, Kim JH, Lee JM, Seo ES. Efficacy of extramedullary femoral component alignment guide system for blood saving after total knee arthroplasty. Knee Surg Relat Res. 2012;24:99-103.

20. Fehring TK, Mason JB, Moskal J, Pollock DC, Mann J, Williams VJ. When computer-assisted knee replacement is the best alternative. Clin Orthop Relat Res. 2006;452:132-6.

21. Klein GR, Austin MS, Smith EB, Hozack WJ. Total knee arthroplasty using computer-assisted navigation in patients with deformities of the femur and tibia. J Arthroplasty. 2006;21:284-8. 